\title{
Effects of para-chlorophenylalanine on food intake in rats*
}

\author{
JAAK PANKSEPP \\ Bowling Green State University, Bowling Green, Ohio 43403
}

and

\author{
DWIGHT M. NANCE \\ Department of Anatomy, School of Medicine, Center for Health Sciences, Los Angeles, California 90024
}

\begin{abstract}
Food intakes, water intakes, and body weights of rats were monitored for up to 30 days during daily intragastric administration of $100 \mathrm{mg} / \mathrm{kg} \mathrm{p}$-chlorophenylalanine. During treatment, food intake was reduced to $50 \%-75 \%$ of control levels, water intake was decreased to about $28 \%$ of control levels, and body weights stabilized at about $80 \%-90 \%$ of control levels. Body weight remained low as long as treatment continued, and animals defended the low body weights against food deprivation and weight gain induced by insulin injections. It is unlikely that the decrease in body weight during PCPA treatment is due to malaise, since anorexia could be prevented by depriving animals of food during the first 2 days of drug treatment.
\end{abstract}

Inhibition of serotonin synthesis with parachlorophenylalanine (PCPA) produces a variety behavioral changes, many of which appear to share the common feature of disinhibition or behavioral hyperresponsiveness. For instance, PCPA can produce intense pansexuality (Ferguson et al, 1970; Tagliamonte et al, 1969), mouse killing in nonkiller rats (Sheard, 1969), increased irritability (Koe \& Weissman, 1966), heightened reactivity to shock (Fibiger et al, 1972; Harvey et al, 1968), decreased habituation to auditory startle Conner et al, 1970a), disruption of passive avoidance (Stevens et al, 1969), faster active avoidance (Tenen, 1967), attenuation of the conditioned emotional response (Hartman \& Geller, 1971), and insomnia (Delorme et al, 1966). However, all the behavioral changes following PCPA do not fit nicely into a disinhibitory framework. For instance, motor activity is often decreased (Tenen, 1967), and some forms of aggression such as shock-induced fighting are not reliably modified (Conner et al, 1970b). Reports in the literature as to the effects of PCPA on feeding and drinking are incomplete and contradictory. Although it has been asserted that PCPA produces hyperphagia in cats (Ferguson et al, 1969), quantitative evidence has yet to be presented. To the contrary, PCPA has been reported to reduce food intake of rats (McFarlain \& Bloom, 1972), but again quantitative data has not been presented. Accordingly, in the following experiments, we systematically assessed the effect of prolonged PCPA treatment on the feeding and drinking of rats. We also assessed the behavior of PCPA-treated animals to two regulatory challenges, insulin and food deprivation.

*This research was supported by NSF Grant GB-40150. Th insulin used in this study was provided as a courtesy of Eli Lilly and Co. and the PCPA as a courtesy of Charles Pfizer \& Co. We wish to thank Thomas Renucci for experimental assistance.

\section{METHOD}

\section{Experiment 1}

Forty-two male Long-Evans hooded rats, approximately 120 days old at the start of experimentation, were used. Animals were individually caged and were allowed free access to powdered Purina Laboratory Chow from spill-proof containers and to water from 100-ml graduated drinking tubes. Lighting was on a diurnal cycle (lights on at 8:00 a.m.; lights off at 8:00 p.m. Animals were divided into six groups matched for body weight. Three groups served as volumetric vehicle controls. From each set of animals, one group $(\mathrm{N}=6)$ was tested under food deprivation, one $(\mathrm{N}=9)$ was to be tested during long-term insulin treatment, and one $(\mathrm{N}=6)$ served as a baseline control. Throughout the experiment, daily food intakes were measured to $0.1 \mathrm{~g}$, water intakes to $1.0 \mathrm{ml}$, and body weights to $1.0 \mathrm{~g}$.

After 8 days of baseline measurements, PCPA treatment was initiated. On the initial day, all animals in drug groups were administered intragastric loads of $200 \mathrm{mg} / \mathrm{kg}$ dl-PCPA (Pfizer) suspended in $0.9 \%$ saline at concentrations of $50 \mathrm{mg} / \mathrm{cc}$. Loading was done with the aid of a 16-ga stainless steel feeding tube (Popper \& Sons, Inc.). On all subsequent days, the daily dose of PCPA was reduced to $100 \mathrm{mg} / \mathrm{kg}$, and treatment was continued for 19 additional days. The drug-free groups received volumetric loads of the saline carrier each day. The intragastric route of drug administration was used in preference to the more widely employed intraperitoneal route to minimize tissue irritation, which is common when PCPA is administered for prolonged periods into the peritoneal cavity.

Ten days after initiation of PCPA treatment, deprivation groups were placed on a limited feeding schedule consisting of $0.5 \mathrm{~h}$ of food each day for 6 consecutive days. Simultaneously, the insulin groups were started on a daily Protamine zinc insulin (Lilly) regimen, which was to consist of $4 \mathrm{U}, 6 \mathrm{U}, 8 \mathrm{U}, 8 \mathrm{U}, 8 \mathrm{U}$, $8 \mathrm{U}$ of insulin on 6 successive days. The daily dose of insulin was administered subcutaneously at the nape of the neck in two equal injections separated by $12 \mathrm{~h}$.

\section{Experiment 2}

Six male Sprague-Dawley albino rats, 90 days old at the start of experimentation, were employed. Three animals were administered PCPA for 30 days as described in Experiment 1. Three animals served as vehicle controls. To obtain pilot data for a prospective study, all animals received intraperitoneal injections of $500 \mathrm{mg} / \mathrm{kg}$ 2-deoxy-D-glucose 5 and 10 days after the start of PCPA treatment. Beginning 12 days after the initiation of drug treatment, all animals were limited to $1 \mathrm{~h}$ of food per day for 4 consecutive days. Beginning on the 25 th day 


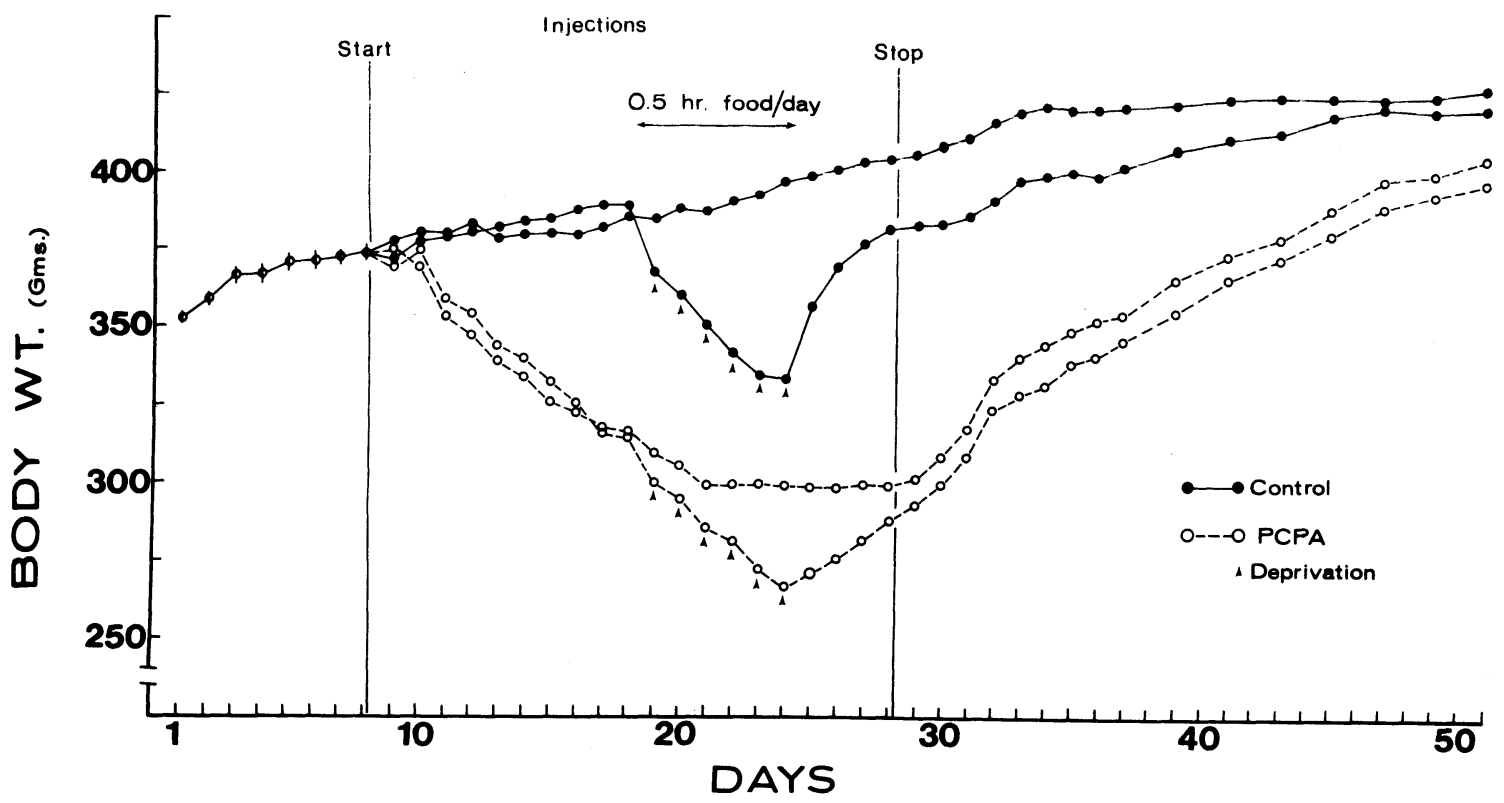

Fig. 1. Mean body weights for Experiment 1. Flags for first 8 days indicate the range of group means.

of treatment, all animals were administered 4,8 , and 8 units of $\mathrm{NPH}$ insulin (Lilly) on 3 successive days. Injections were administered as in Experiment 1. Upon termination of insulin treatment, ad lib food consumption was measured for 3 days. On the last day of PCPA treatment, all animals were sacrificed, and brains were removed and frozen for brain serotonin analysis. Spectrophotoflurometric analysis of serotonin (Maickel, Lox, Saillant, \& Miller, 1968) was performed on three parts of each brain: (1) telencephalon, (2) the diencephalon from septum to the superior colliculus, and (3) the brainstem caudal to the superior colliculus.

\section{Experiment 3}

Twelve male Sprague-Dawley albino rats, weighing 277-320 g, were employed. Animals were tested for 4 days. On the first day, daily ad lib food intake and body weights of all animals were measured. At the beginning of the second day, all animals were placed on food deprivation, and six of the animals were injected intragastrically with $200 \mathrm{mg} / \mathrm{kg}$ PCPA; $100 \mathrm{mg} / \mathrm{kg}$ was administered on the next 2 days. The remaining animals received equivolumetric loads of the saline carrier. Food deprivation continued for 2 days, and 24-h refeeding intake was measured on the fourth day.

\section{RESULTS}

\section{Experiment 1}

Mean body weights of control and deprivation groups for the duration of the experiment are presented in Fig. 1. Average daily food and water intakes for these animals during the 6 days prior to the start of PCPA treatment (Days 3-8, Fig. 1), for the 6 days prior to the start of deprivation (Days 13-18), for the 6 days of deprivation (Days 19-24), and for the first 3 days of refeeding (Days 25-27) are presented in Table 1. The PCPA treatment produced an unambiguous depression in

Table 1

Food (Grams) and Water (Milliliters) Intakes for Experiment I

\begin{tabular}{|c|c|c|c|c|c|c|}
\hline \multicolumn{2}{|c|}{ Groups } & $\mathbf{N}$ & $\begin{array}{l}\text { Pre-PCPA } \\
\text { (Days 3-8) }\end{array}$ & $\begin{array}{c}\text { Ad Lib } \\
\text { (Days 13-18) }\end{array}$ & $\begin{array}{c}\text { Deprivation } \\
\text { (Days 19-24) }\end{array}$ & $\begin{array}{l}\text { Postdeprivation } \\
\text { (Days 25-27) }\end{array}$ \\
\hline & & & \multicolumn{4}{|c|}{ Food Intake } \\
\hline Saline & $\begin{array}{l}\text { Control } \\
\text { Deprived }\end{array}$ & $\begin{array}{l}6 \\
6\end{array}$ & $\begin{array}{l}21.9 \pm 0.9 \\
23.6 \pm 1.2\end{array}$ & $\begin{array}{l}18.9 \pm 1.9 \\
19.6 \pm 1.8\end{array}$ & $\begin{array}{r}21.1 \pm 1.7 \\
5.0 \pm 1.4\end{array}$ & $\begin{array}{l}20.6 \pm 1.3 \\
25.0 \pm 0.9\end{array}$ \\
\hline \multirow[t]{2}{*}{ PCPA } & $\begin{array}{l}\text { Control } \\
\text { Deprived }\end{array}$ & $\begin{array}{l}6 \\
6\end{array}$ & $\begin{array}{l}23.0 \pm 1.0 \\
23.0 \pm 1.5\end{array}$ & $\begin{array}{r}9.6 \pm 2.3^{*} \\
10.1 \pm 2.3^{*}\end{array}$ & $\begin{aligned} 10.0 & \pm 2.8^{*} \\
3.0 & \pm 1.3^{* * *}\end{aligned}$ & $\begin{array}{l}14.1 \pm 0.6^{* *} \\
16.8 \pm 2.0^{* *}\end{array}$ \\
\hline & & & \multicolumn{4}{|c|}{ Water Intake } \\
\hline Saline & $\begin{array}{l}\text { Control } \\
\text { Deprived }\end{array}$ & $\begin{array}{l}6 \\
6\end{array}$ & $\begin{array}{l}33 \pm 2 \\
35 \pm 2\end{array}$ & $\begin{array}{l}29 \pm 2 \\
30 \pm 2\end{array}$ & $\begin{array}{l}32 \pm 2 \\
21 \pm 4\end{array}$ & $\begin{array}{l}34 \pm 1 \\
43 \pm 6\end{array}$ \\
\hline PCPA & $\begin{array}{l}\text { Control } \\
\text { Deprived }\end{array}$ & $\begin{array}{l}6 \\
6\end{array}$ & $\begin{array}{l}34 \pm 2 \\
32 \pm 2\end{array}$ & $\begin{array}{l}21 \pm 4^{* *} \\
22 \pm 3^{* *}\end{array}$ & $\begin{array}{l}18 \pm 3^{* *} \\
10 \pm 2 *\end{array}$ & $\begin{array}{l}27 \pm 2^{* *} \\
30 \pm 6 * *\end{array}$ \\
\hline
\end{tabular}

Note-Days refer to Fig. 1; values are means $\pm S D$.

${ }^{*} p<.001{ }^{* *} p<.01{ }^{* * *} p<.05$, drug vs appropriate no-drug group, $t$ test 
food intake to about $50 \%$ of pretreatment levels and a concurrent decline in body weight. Water intake was decreased to a smaller extent (approximately 28\%). The body weight of PCPA-treated animals stabilized at about $80 \%$ of control weight and showed no tendency to recover for the duration of PCPA treatment. When drug treatment was terminated, animals overate and gradually regained the lost weight.

Data for insulin-treated animals will not be presented in full, because before the projected period of insulin treatment could be completed, seven of nine PCPA animals had died. No fatalaties occurred in the control group. Five animals died within the first 3 days of treatment, and two died on the fourth day. Accordingly, treatment of the two surviving animals was terminated. Of the five animals which died during the first 3 days, none exhibited overeating in response to insulin. In fact, all ate less during insulin than prior to treatment. The two animals which died later, as well as the two surviving animals, exhibited overeating to insulin. For instance, on the last 2 days of insulin treatment ( $8 \mathrm{U} /$ day), the two surviving animals ate an average of $40.5 \mathrm{~g}$ per day as compared to preinsulin intake of $17.4 \mathrm{~g}$ per day (mean of 2 days prior to insulin). On the second and third days following termination of insulin treatment, the intakes of these animals dropped to an average of $7.5 \mathrm{~g}$ per day. These values are comparable to the data of control animals, all of which exhibited hyperphagia during insulin and hypophagia after cessation of treatment.

\section{Experiment 2}

Mean food intakes and body weights are depicted in
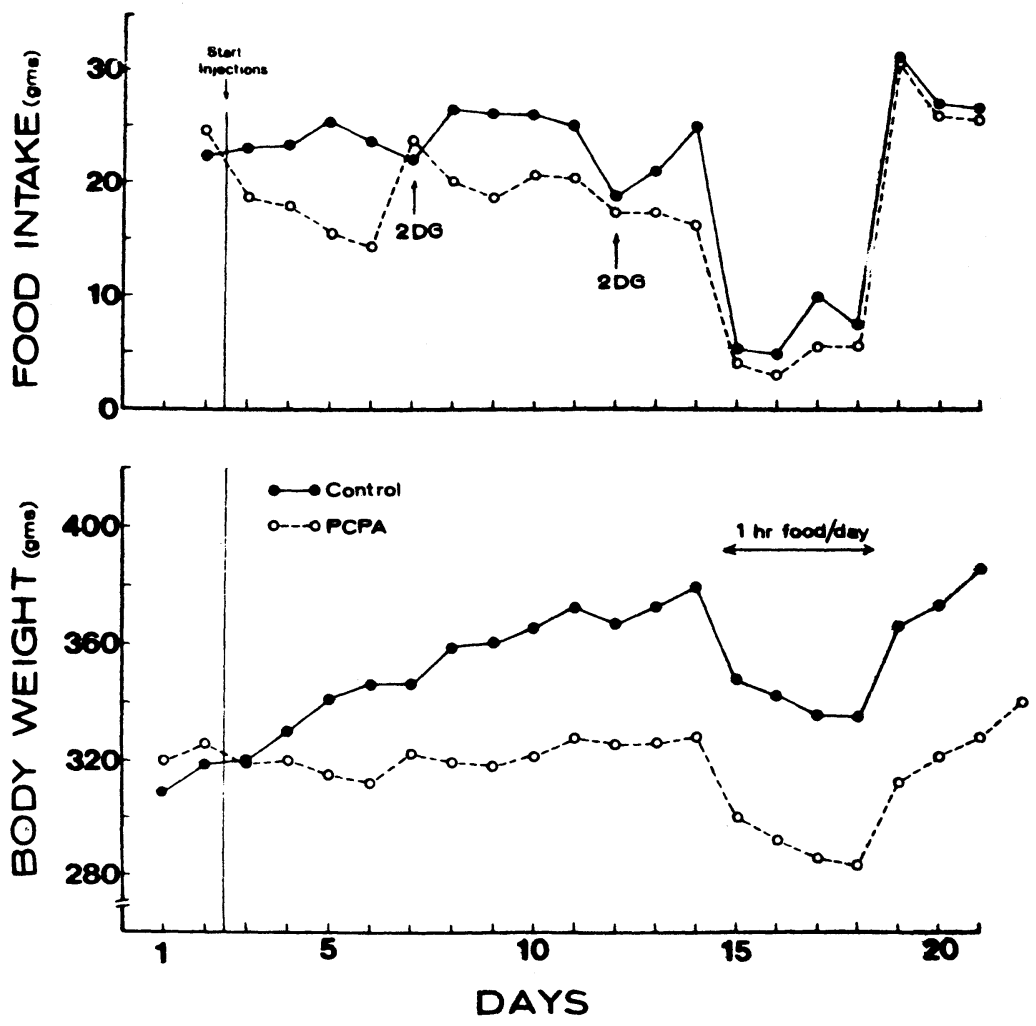

Fig. 2. These data essentially replicate the previous experiment, but there was one difference. In the previous experiment PCPA animals lost weight, while in this experiment they failed to gain weight. The difference may be due to the use of younger and lighter animals in this experiment. It may also be noted that on the days animals received $500 \mathrm{mg} / \mathrm{kg}$ 2-deoxy-D-glucose, PCPA-treated animals tended to eat more while control animals ate less.

Food intake during insulin treatment is depicted in Fig. 3. Insulin increased food consumption and body weight of both groups. The increased weight was lost by a compensatory decrease in food intake when insulin treatment was terminated.

Biochemical analyses indicated that brain serotonin levels of PCPA-treated animals were less than $23 \%$ of control levels (Table 2).

\section{Experiment 3}

The mean $( \pm S D)$ food intake of control animals on the day prior to deprivation was $21.7( \pm 2.9) \mathrm{g}$ and on the day following the 48 -h fast, $24.0( \pm 3.0) \mathrm{g}$. The corresponding values for the PCPA-treated group were $23.0( \pm 2.8)$ and $25.0( \pm 3.2) \mathrm{g}$. By comparison, feeding in nondeprived animals at comparable points in time were $59 \%$ (Experiment 1) and 62\% (Experiment 2) of predrug levels.

\section{DISCUSSION}

Chronic PCPA treatment reduces food intake, water intake, and body weight of rats. Since food intake is
Fig. 2. Mean food intakes and body weights for Experiment 2. 


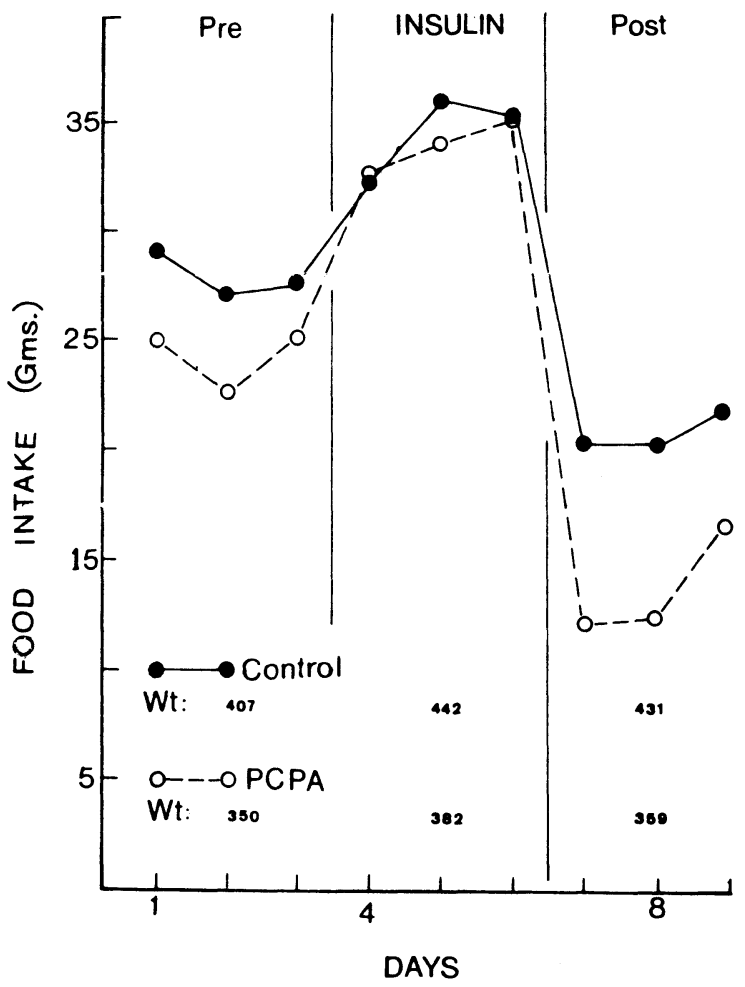

Fig. 3. Mean food intakes for 3 days prior to insulin treatment, for 3 days during insulin $(4,8$, and 8 units/day), and for 3 postinsulin days. Mean body weights for the last day of each period are indicated.

reduced more than water intake, it is likely that the main effect is to reduce hunger rather than thirst. In line with such a conclusion, our attempts to reverse PCPA-induced anorexia by forced loading of water have been without success. Likewise, humans treated with PCPA report a loss of appetite (VanWoert, Ambani, \& Levine, 1972).

Within the course of the present experiment, there was no tolerance to the weight-reducing effect of PCPA. The animals remained at $80 \%-90 \%$ of control levels for the duration of treatment. They also defended this lower body weight in response to imposed regulatory challenges. After food deprivation, they overate and recovered lost weight. After weight gain induced by insulin treatment, they exhibited compensatory reduction of food intake and a concomitant fall of body weight. In demonstrating this last point, we were confronted by a noteworthy peculiarity of PCPA-treated animals. They were deficient in the behavioral or physiological resources needed to resist insulin coma. A significant proportion of PCPA-treated animals died during the treatment. These deaths cannot be attributed merely to their low body weights, for the same insulin regimen has been successfully employed in normal animals lighter than the ones which died (personal observation). Since a common complaint voiced by humans administered PCPA is tiredness and weakness (Cremata \& Koe, 1966; Sjoerdsma, 1970; Van Woert et al, 1972), it is possible that our rats experienced
Table 2

Brain Serotonin Concentrations (ug/g) Following 30 Days of Treatment With PCPA as Described in Experiment II

\begin{tabular}{llll}
\hline & \multicolumn{3}{c}{ Amine Concentration in } \\
Treatment & Telencephalon & Diencephalon & Brain Stem \\
\hline Control & $0.536 \pm .010$ & $1.026 \pm .044$ & $0.932 \pm .105$ \\
PCPA & $0.126 \pm .057^{*}$ & $0.199 \pm .081^{*}$ & $0.218 \pm .064^{*}$ \\
\hline
\end{tabular}

Note-Values are means $\pm S D, N=3$ for both treatments. ${ }^{*} p<.001, t$ test for independent groups.

similar symptoms and that the further imposition of a tendency toward hypoglycemia may have produced lassitude beyond the animals' ability to cope.

Whether the observed anorexia should be attributed to reduction of brain serotonin or to other effects of PCPA cannot yet be decided. At least four alternative possibilities to a central action should be considered: (1) PCPA reduces serotonin not only in the brain, but also within the gastrointestinal tract and other tissues (Koe \& Weissman, 1966). (2) PCPA also inhibits phenylalanine hydroxylase, leading to abnormally high blood phenylalanine levels (Lipton, Gordon, Guroff, \& Undenfriend, 1967). (3) Metabolites of PCPA may suppress feeding. In line with such a possibility, Stark and Fuller (1972) have presented evidence that such products of PCPA metabolism as 3-chlorotyrosine and 3-chlorotyramine can inhibit self-stimulation behavior in rats. (4) The PCPA effect on feeding may be due to illness. Although our experimental animals appeared perfectly healthy, PCPA treatment has been reported to produce side effects such as nausea and abdominal pain in human patients (Cremata \& Koe, 1966; Van Woert et al, 1972). However, our data argues against such causality since food-deprived animals receiving PCPA did not exhibit anorexia (Experiment 3).

Finally, we would like to discuss the possibility that PCPA reduces feeding as a direct consequence of reduced brain serotonin. There are some compelling lines of argument which suggest this possibility. For instance, the feeding behavior of animals treated with PCPA and animals with small hypothalamic lesions just lateral to the fornix columns (Powley \& Kessey, 1970) are similar. Both preparations maintain and defend body weight below control levels. Furthermore, the location of weight-reducing perifornical lesions (Powley \& Keesey, 1970 ) is within the trajectory of a serotonergic fiber bundle. Histoflourescence mapping has demonstrated a serotenergic fascicle concentrated just lateral to the fornix bundle (Fuxe, Hökfelt, \& Ungerstedt, 1970), and lesions in this general area are known to markedly reduce forebrain serotonin levels (Harvey \& Lints, 1971; Sheard \& Freedman, 1966/67). Attenuation of activity within this system may be the common feature of the anorexia which results from midlateral hypothalamic lesions and PCPA treatment. Additional inferential support for this general line of reasoning can be culled from biochemical changes in brain serotonin activity which occur concurrently with satiation. The synthesis rate of brain serotonin is about 30\% lower in fed rats 
than in fasted rats (Perez-Cruet, Tagliamonte, Tagliamonte, \& Gessa, 1972). Moreover, this period of decreased synthesis is accompanied by decreased neuronal utilization of serotonin, as indicated by the low 5-hydroxyindoleacetic acid levels (Perez-Cruet et al, 1972).

Behavioral results obtained from animals with serotonin-depleting lesions of the rostral raphe nuclei are only partially congruent with the above reasoning. Since ascending serotonergic systems in the brain are derived exclusively from midline raphe nuclei of the brainstem (Fuxe et al, 1970), it might be expected that destruction of those cells would also lead to a chronic reduction of body weight. In fact, the lesions do produce a period of weight reduction, but gradually the animals recover normal body weights and exhibit normal daily food intakes (Coscina, Grant, Balagura, \& Grossman, 1972; Lorens, Sorensen, \& Yunger, 1971).

In summary, chronic treatment of rats with PCPA produces a very systematic reduction in their feeding behavior. These animals also appear to actively defend their lower body weights. Although the reduction in feeding behavior may be due to effects other than reduction of brain serotonin, much of our present knowledge about the brain serotonergic systems is consistent with the notion that PCPA may be reducing appetite by attenuating activity in a serotonergic neural system which courses through the midlateral hypothalamus. Accordingly, it will be informative to determine whether PCPA-induced anorexia can be modified with lesions of the perifornical hypothalamus or raphe nuclei.

\section{REFERENCES}

Conner, R. L., Stolk, J. M., Barchas, J. D., Dement, W. C., \& Levine, S. The effect of parachlorophenylalanine on shock-induced fighting behavior in rats. Physiology \& Behavior, 1970, 5, 1221-1224.

Behavior, 1970, 5, 1221-1224.
Conner, R. L., Stolk, J. M., Barchas, J. D., \& Levine, S. $P$ arachlorophenylalanine and habituation to repetitive auditory startle stimuli in rats. Physiology \& Behavior, 1970, 5, 1215-1219.

Coscina, D. V., Grant, L. D., Balagura, S., \& Grossman, S. P. Hyperdipsia after serotonin-depleting midbrain lesions. Nature New Biology, 1972, 235, 63-64.

Cremata, V. Y., \& Koe, B. K. Clinical-pharmacological evaluation of p-chlorophenylalanine: A new serotonin-depleting agent. Clinical Pharmacology \& Therapeutics, 1966, 7, 768-776.

Delorme, F., Froment, J. L., \& Jouvet, M. Suppression du sommeil par la p-chloromethamphetamine et p-chlorophenylalanine. Comptes Rendus Seances de la Societé de Biologie et de ses Filiales (Paris), 1966, 160, 2347-2351.

Ferguson, J., Henriksen, S., Cohen, H., Hoyt, G., Mitchell, G., McGarr, K., Rubenson, D., Ryan, L., \& Dement, W. The effect of chronic administration of para-chlorophenylalanine on the behavior of cats. Psychophysiology, 1969, 6, 221.
Ferguson, J., Henriksen, S., Cohen, H., Mitchell, G., Barchas, J., \& Dement, W. C. "Hypersexuality" and behavioral changes in cats caused by administration of p-chlorophenylalanine. Science, 1970, 168, 449-501.

Fibiger, H.C., Mertz, P. H. \& Campbell, B. A. The effect of para-chlorophenylalanine on aversion thresholds and reactivity to foot shock. Physiology \& Behavior, 1972, 8, 259-263.

Fuxe, K., Hökfelt, T. \& Ungerstedt, U. Morphological and functional aspects of central monoamine neurones. International Review of Neurobiology, 1970, 13, 93-126.

Hartmann, R. J., \& Geller, I. P-chlorophenylalanine effects on a conditioned emotional response in rats. Life Sciences, 1971, 10,927-933.

Harvey, J. A., \& Lints, C. E. Lesions in the medial forebrain bundle: Relationship between pain sensitivity and telencephalic content of serotonin. Journal of Comparative \& Physiological Psychology, 1971, 74, 28-36.

Harvey, J. A., Lints, C. E., \& Grabarits, F. Pain sensitivity and brain serotonin: Effects of brain lesions, p-chlorophenylalanine and 5-hydroxytryptophan. Pharmacologist, 1968, 10 211.

Koe, B. K., \& Weissman, A. p-chlorophenylalanine: Specitic depletor of brain serotonin. Journal of Pharmacology \& Experimental Therapeutics, 1966, 154, 499-516.

Lipton, M. A., Gordon, R., Guroff, G., \& Undenfriend, S P-chlorophenylalanine-induced chemical manifestation of phenylketonuria in rats. Science, $1967,156,248-250$.

Lorens, S. A., Sorensen, J. P., \& Yunger, L. M. Behavioral and neurochemical effects of lesions in the raphe system of the rat. Journal of Comparative \& Physiological Psychology, $1971,77,48-52$.

Maickel, R. P., Cox, R. H., Saillant, J., \& Miller, F. P. A method for the determination of serotonin and norepinephrine in discrete areas of rat brain. International Journal of Neuropharmacology, 1968, 7, 275-281.

McFarlain, R. A., \& Bloom, J. M. The effects of para-chlorophenylalanine on brain serotonin, food intake, and U-maze behavior. Psychopharmacologia, 1972, 27, 85-92.

Perez-Cruet, J., Tagliamonte, A., Tagliamonte, P., \& Gessa, G. L. Changes in brain serotonin metabolism associated with fasting and satiation in rats. Life Sciences, 1972, 11, 1-39.

Powley, T. L., \& Keesey, R. E. Relationship of body weight to the lateral hypothalamic feeding syndrome. Journal of Comparative \& Physiological Psychology, 1970, 70, 25-36.

Sheard, M. H. The effect of p-chlorophenylalanine on behavior in rats: Relation to brain serotonin and 5-hydroxyindoleacet acid. Brain Research, 1969, 15, 524-528.

Sheard, M. H., \& Freedman, D. X. The effects of CNS lesions on norepinephrine, serotonin, and acetylcholine in brain. Brain Research, 1966/67, 3, 292-294.

Sjoerdsma, A. Serotonin now: Clinical implications of inhibiting its synthesis with para-chlorophenylalanine. Annals of Internal Medicine, 1970, 73, 607-629.

Stark, P., \& Fuller, R. W. Behavioral and biochemical effects of p-chlorophenylaianine, 3-chlorotyrosine and 3-chlorotyramine. A proposed mechanism for inhibition of self-stimulation. Neuropharmacology, 1972, 11, 261-272.

Stevens, D. A., Fechter, L. D., \& Resnick, O. The effects of p-chlorophenylal ınine, a depletor of brain serotonin on behavior: II. Retardation of passive avoidance learning. Life Sciences, 1969, 8, 379-385.

Tagliamonte, A., Tagliamonte, P., Gessa, G., \& Brodie, B. Compulsive sexual activity induced by p-chlorophenylalanine in normal pinealectomized male rats. Science, 1969,166 , 1433-1435.

Tenen, S. The effects of p-chlorophenylalanine, a serotonin depletor, on avoidance acquisiton, pain sensitivity and related behavior in the rat. Psychopharmacologia, 1967, 10, 204-219.

Van Woert, M. H., Ambani, L. M., \& Levine, R. J. Clinical effects of para-chlorophenylalanine in Parkinson's disease. Diseases of the Nervous System, 1972, 33, 777-780.

(Received for publication October 11, 1973; revision received May 23, 1974.) 